\title{
Jujube (Ziziphus jujuba Mill.) Flowering and Fruiting in the Southwestern United States
}

\author{
Shengrui Yao', Junxin Huang, and Robert Heyduck \\ Department of Plant and Environmental Sciences, Sustainable Agriculture \\ Science Center at Alcalde, New Mexico State University, Alcalde, NM 87511
}

Additional index words. blooming type, blooming process, self-pollination, self-fertility, seed development

\begin{abstract}
Fifty-six jujube cultivars were observed for their flowering habits and fruiting characteristics at Alcalde, New Mexico. Jujube cultivars were classified as morning blooming type or afternoon blooming type. Among the 56 cultivars observed, 24 belonged to the morning type and 32 belonged to the afternoon type. Eighteen out of the 56 cultivars had their blooming type reported for the first time. The sepal splitting for morning type occurred from sunrise to $1000 \mathrm{HR}$, whereas it occurred between 1300 and $1600 \mathrm{HR}$ for the afternoon type. Even though their opening time differed, pollen release happened during daytime for both-morning type released pollen in the afternoon and afternoon type released pollen in the late afternoon and the next morning. Rainy and cloudy weather delayed blooming for several hours. Each flower experienced the following stages during blooming: sepal splitting, sepal flat, petal standing, petal and anther separation, petal flat and anther standing, anther flat, and stigma browning; the time and duration of each stage varied with cultivar and blooming type. Flower size varied by cultivar and helps with cultivar identification. Cultivars Li, Li-2, Redland, Qiyuexian, Xiangzao, Teapot, and Daguazao were self-pollinating/self-fruitful in New Mexico. For open pollination, fruit set varied greatly by cultivar. 'Abbeville' had the best fruit set each year. Most cultivars had better fruit set from open pollination than selfpollination; however, self-fruitful cultivars $\mathrm{Li}, \mathrm{Li}-2$, and Redland had better fruit set with self-pollination than open pollination in some years. Open pollination increased fruit size for all cultivars. 'Zhongning', 'Abbeville', 'Jinsi-2', and 'Globe' had high seed percentage from open-pollinated fruit, whereas 'Lang', 'Don Polenski', 'Junzao', and 'Xingguang' did not produce fully developed seed in any years but some dark brown empty seedcoat sacs. Seed development was also affected by weather and pollination conditions. Fruit blooming type, pollen release, self-pollination, self-fruitfulness, selffertility, and seed development are all critical information for jujube breeders, researchers, extension personnel, and growers.
\end{abstract}

Jujubes (Ziziphus jujuba Mill.), also called chinese dates, belong to the Rhamnaceae family. Jujube cultivars were first imported into the United States by U.S. Department of Agriculture (USDA) agricultural explorer Frank N. Meyer from 1908 to 1918 (Meyer, 1911; Thomas, 1924; Yao, 2013). In the past hundred

Received for publication 30 Jan. 2015. Accepted for publication $21 \mathrm{Apr} .2015$.

This project is partially supported by the USDA Specialty Crop Block Grant through the New Mexico Department of Agriculture. This project is also a contribution of the New Mexico Agricultural Experiment Station.

We thank Rolston St. Hilaire, Richard Heerema, and Steve Guldan from New Mexico State University for their critical review of the manuscript. We also thank David Archuleta, David Salazar, Estevan Herrera, Margarito Hernandez, Bingye Xue, and Jenny Xue for technical assistance. We also like to extend our special thanks to Dr. G. Wang from Research Institute of Forestry, the Chinese Academy of Forestry, who collected the jujube cultivars in China for this project.

${ }^{1}$ To whom reprints should be addressed; e-mail yaos@nmsu.edu. years, jujubes were cultivated mainly in the southwest, southern, and southeastern states from North Carolina, South Carolina to Florida, and from Florida and Georgia all the way to California; but they had been reportedly grown as far north as Pennsylvania (Ashton, 2006, 2008; Atkins, 1987; Locke, 1948, 1955; Lyrene, 1979, 1983; Yao, 2013). Recently, we noticed some jujube trees along the historic Chinese railroads or mine worker campsites in the southwest (Yao, 2015). Dry jujubes were part of those Chinese workers' diet and the littered seeds left behind grew voluntarily. Local people did not know much about jujubes but kept the trees that produced large and good-tasting fruit. These volunteer seedling plants belong to $Z$. jujuba and could be good germplasm for new cultivar selections.

Early researchers had identified that jujube grew and produced well and had great potential in the southwestern United States (Fairchild, 1918; Hager and Edward, 1989; Lanham, 1926; Locke, 1948, 1955; Meyer, 1916; Sweet, 1985). Because of various reasons, however, jujube production is still limited. Recently, interest in jujubes from growers and consumers is surging, and nurseries have had a hard time meeting the market demand (Ron Ludekens, personal communication). The challenges now are very limited commercially available cultivars and research support. Growers are frustrated due to insufficient information on cultivars, cultural management, processing, and marketing.

There are over 800 jujube cultivars known in China (Guo and Shan, 2010; Liu, 2008) while there are only a few cultivars commercially available in the United States with 'Li' and 'Lang' as the two most dominant. All jujube growers request more cultivars to extend the fruit supply season and to be used for different purposes to meet the consumers' demand (Yao, 2013).

Unlike apple or peach, jujube flowers are not initiated the previous year but the same year as they bloom. As the flexible deciduous fruiting structure-branchlets grow, they initiate flowers (Yao, 2012a). Jujubes have tiny flowers of $\approx 6 \mathrm{~mm}$ in diameter and have many more flowers than most fruit crops (Guo and Shan, 2010; Liu, 2006; Yao, 2012a). Each branchlet can have from 20 to over 100 flowers depending on the cultivar. Branchlet growth, flower initiation, blooming, fruit setting, and fruitlet growth occur simultaneously. Because of the high nutrient competition, jujubes, in general, have low fruit set (Guo and Shan, 2010).

In the 1950s, the USDA Chico Plant Introduction Station had a jujube breeding program for some years; unfortunately, the Chico Station was closed in the late 1950s. During their jujube breeding/cultivar selection process, they mentioned the need for a complete understanding of flowering, pollination, selfsterility, and seed development and conducted some preliminary research on these topics (Ackerman, 1961). Yan et al. (2009, 2010) reported the fruiting characteristics of more than 100 Chinese cultivars. In the United States, the flowering and fruiting habits of existing cultivars and new importations are largely unknown, and this fundamental knowledge would be critical for jujube breeders and researchers. Extension personnel and growers also need this information for cultivar recommendations or cultivar selections.

The New Mexico State University (NMSU) Sustainable Agriculture Science Center at Alcalde, New Mexico, has imported 30+ jujube cultivars from China and collected a number of cultivars in the United States for a total of over 50 cultivars. The objective of this study is to examine the blooming types, flowering characteristics, self-pollination/self-fertility, and seed development of these cultivars.

\section{Materials and Methods}

This experiment was conducted at the NMSU Sustainable Agriculture Science Center at Alcalde, New Mexico (lat. 36 $05^{\prime} 27.94^{\prime \prime}$ $\mathrm{N}$, long. $106^{\circ} 03^{\prime} 24.56^{\prime \prime} \mathrm{W}$, and $1737 \mathrm{~m}$ elevation) and all cultivars used are listed in Table 1. Since trees were planted or grafted in different years, not all cultivars were used for every test in this study (cultivars used are clearly listed for each experiment). Among those cultivars, Abbeville, Lang, Li, Sihong, 
Table 1. Jujube cultivars used in this study and their blooming types at New Mexico State University's Sustainable Agriculture Science Center at Alcalde, New Mexico.

\begin{tabular}{|c|c|c|c|c|c|}
\hline Cultivar & Blooming type & Source & Cultivar & Blooming type & Source \\
\hline Abbeville & $\mathrm{AM}$ & Louisiana & $\mathrm{Li}-2$ & PM & California \\
\hline Ant Admiral & $\mathrm{PM}$ & China & Liuyuexian & $\mathrm{PM}$ & China \\
\hline Banzao & PM & China & Maya & PM & China \\
\hline Chaoyang & PM & China & Miyun & PM & China \\
\hline Chico & $\mathrm{AM}$ & California & $\mathrm{Mu}$ & $\mathrm{AM}$ & California \\
\hline Dabailing & PM & China & Mopanzao & $\mathrm{AM}$ & China \\
\hline Daguazao & PM & China & Pitless & PM & China \\
\hline Don Polenski & $\mathrm{AM}$ & California & Qiyuexian & PM & China \\
\hline Dragon & PM & China & Redland & PM & California \\
\hline Edhegard & $\mathrm{AM}$ & Alabama & Russia-2 & $\mathrm{AM}$ & California/Russia \\
\hline Fitzgerald & $\mathrm{AM}$ & Georgia & September Late & PM & California/China \\
\hline Fuping & $\mathrm{AM}$ & China & Shanxi Li/Linyi Li & PM & China \\
\hline GA-866 & PM & California & Sherwood & PM & Louisiana \\
\hline GI-1183 & $\mathrm{AM}$ & California & Shuimen & $\mathrm{AM}$ & California/China \\
\hline Globe & $\mathrm{AM}$ & China & Sihong & PM & California/China \\
\hline Honeyjar & PM & China & So & $\mathrm{AM}$ & California \\
\hline Hupingzao & $\mathrm{AM}$ & China & Sugarcane & $\mathrm{AM}$ & California \\
\hline Jin & PM & China & Sui & $\mathrm{AM}$ & California \\
\hline Jinkuiwang & PM & China & Teapot & PM & China \\
\hline Jing-39 & $\mathrm{AM}$ & China & Topeka & $\mathrm{PM}$ & Kansas \\
\hline Jinsi-2 & PM & China & Tsao & PM & Pennsylvania \\
\hline Jinsi-3 & PM & China & Thornless & $\mathrm{AM}$ & California \\
\hline Jinsi-4 & $\mathrm{PM}$ & China & Xiangzao & $\mathrm{AM}$ & China \\
\hline Jixin & $\mathrm{AM}$ & China & Xingguang & $\mathrm{AM}$ & China \\
\hline Junzao & $\mathrm{AM}$ & China & Youzao & PM & China \\
\hline Kongfucui & PM & China & Yuanling & PM & China \\
\hline Lang & $\mathrm{AM}$ & California & Zaocuiwang & $\mathrm{AM}$ & China \\
\hline $\mathrm{Li}$ & PM & California & Zhongning & PM & China \\
\hline
\end{tabular}

Shuimen, Shanxi Li, Globe, Redland, Don Polenski, Fitzgerald, and So were planted in 2006, whereas 'Jin', 'Sui', and 'Topeka' were planted in 2011. Also in 2011, another 30 cultivars were imported from China as scionwood and grafted to wild jujube sucker rootstocks that had been planted in 2010 . Because of the needs from researchers and growers and limited adult trees at Alcalde, New Mexico, we used young trees for part of the experiment. Another reason for using young trees is jujube's precocity - they can bear fruit during grafting year or planting year.

The planting density for the 2006 planting was $1.8 \times 3.6 \mathrm{~m}$, whereas the imported cultivars were grafted in the nursery area with spacing of $1.2 \times 1.8 \mathrm{~m}$. From 2012 to 2014 , trees from both locations were used for the flowering habits and self-pollination/selffertility studies. Trees from a 2011 replicated planting with 'Li', 'Lang', 'Sugarcane', 'Honeyjar', 'So', 'Shanxi Li', 'Li-2', 'September Late', and 'GA-866' at $1.8 \times 3.6 \mathrm{~m}$ spacing were also used for the self-pollination/self-fertility experiment. Trees were fertilized two to three times in late May to June each year at a rate of $33-45 \mathrm{~kg} \mathrm{~N} / \mathrm{h}$ a and irrigated weekly depending on season and precipitation.

Jujube flower number and blooming type. In 2012, 10 jujube branchlets (flexible deciduous fruiting branches) (Yao, 2012a) were sampled for 25 cultivars on 15 June. Total nodes and flower number at each node were counted and averaged for each cultivar. Flower diameter of 15 flowers for 46 cultivars was measured in 2012 and 2014. Jujube blooming times were observed at 3-4 dates in late June to early July each year for all cultivars from 2012 to 2014 . At each date, the flower-blooming process was monitored hourly from 0600 to $1700 \mathrm{HR}$ and at 2200, 0300, and $0500 \mathrm{HR}$. Four or five flowers per cultivar were harvested, stored in $1.5-\mathrm{mL}$ tubes and brought back to the laboratory for pictures. The flower-blooming sequence was photographed hourly from 0600 to $1700 \mathrm{HR}$ for 'Li', 'Lang', 'Sugarcane', 'Sihong', and 'Abbeville' in July 2013 with a Cole Parmer digital microscope (Vernon Hills, IL). Their pollen release, stigma changes, and nectar exudation were monitored during this process.

Cultivar self-pollination/self-fertility studybagging experiment. Four to ten 1- to 3-yearold secondary branches of 40-45 cultivars were selected and half of them were randomly chosen for bagging on 6-7 June 2012, 8-10 June 2013, and 22-25 June 2014, whereas the other half were left for open pollination without bagging. For those bagged branches, cultivar was self-pollinated naturally without any further hand pollination. Spatially, secondary branches from southeast, south, and southwest aspects of trees were chosen instead of those on the north side to avoid shading. In 2012, red nylon seed bags of $30 \times 50 \mathrm{~cm}$ or $40 \times 60 \mathrm{~cm}$ were used for bagging with mesh size of $1.5-2 \mathrm{~mm}$. Since 2013 , pollination bags of $45 \times 50 \mathrm{~cm}$ with opening of $0.5-0.8 \mathrm{~mm}$ in length replaced the seed bags in the bagging experiments because they could block all insects (Middletown, DE). All opened flowers were removed from selected branches for either bagging or open pollination, and bags were twist-tied at the end. Branchlet number for each secondary branch was counted at treatment time. Bags were kept in place for 6 weeks and removed in late July (early Aug. in 2014). Some cultivars still had a few flowers or flower buds remaining at the end of 6 weeks, and they were removed during the unbagging process. Fruit sets were counted in August, late
September, and at harvest. Total fruit weight and fruit number were recorded per treatment per cultivar at harvest.

Cultivar seed development. Harvested fruit from bagged or open-pollinated branches from 2012 to 2014 were air-dried, and the pits (stones) were cracked and their seed conditions were evaluated as fully developed seed, aborted seed, or no seed. Fully developed seeds are filled seeds; aborted seeds are dried, dark brown seedcoat sacs only; and no seed means no visible seed or seedcoat inside the stone.

Jujube flower diameters were averaged by cultivar and standard errors were calculated. Cultivar fruit set was calculated as fruit number per 100 branchlets. Seed development was calculated as filled seed or aborted seed percentage. Average among years and standard error were calculated for cultivar fruit set and seed percentage.

\section{Results}

Flower number and flower size. Flower number at each node varied greatly by cultivar (Fig. 1), but was relatively stable for each cultivar from year to year. 'Zhongning', 'Li', 'Li-2', 'Shanxi Li', 'Redland', 'Daguazao', 'Shuimen', 'Globe', and 'Abbeville' had fewer flowers than others with only one to three flowers per node. 'Liuyuexian', 'Sihong', 'Jinsi-2', 'Miyun', 'Sugarcane', and 'Jinsi-3', on the other hand, had more than seven flowers in the middle section of the branchlets (Fig. 1). 'Fitzgerald' had the highest number of flowers with 13 per node in the middle section of the branchlet. The branchlet length and number of nodes varied with cultivar, weather, and nutritional levels.

Jujube flowers are small without showy petals. Its flower diameters ranged from 5 to 7 mm (Table 2). 'GA-866', 'Chaoyang', 'Sui', 'Zaofengcui', 'Globe', 'Maya', and 'Honeyjar' had small flowers with diameters $<6 \mathrm{~mm}$, whereas 'Lang', 'Jing-39', and 'Dragon' had big flowers with diameters $>7 \mathrm{~mm}$. Most cultivars had flower diameters between 6 and $7 \mathrm{~mm}$. Flower size for each cultivar is relatively constant and can be used as a supplemental trait for cultivar identification.

Flower blooming type. Jujube cultivars can be classified as two blooming typesmorning blooming or afternoon blooming based on their sepal splitting/opening time (Table 1). For the morning type, their sepals split from sunrise to $1000 \mathrm{HR}$, whereas for the afternoon type it is usually from 1300 to $1600 \mathrm{HR}$. Among the 56 cultivars observed, 24 were morning blooming type and 32 were afternoon type (Table 1). Most cultivars, except 'Mopanzao' and 'Teapot', had all sepals opened/split at the same time with even recess; 'Mopanzao' and 'Teapot' normally had partial opening with two to three sepals opened earlier than others.

Flower blooming time for each cultivar was relatively consistent from day to day and from year to year at one location. Rain and cloudy weather delayed the blooming process, but cultivars with the same blooming 


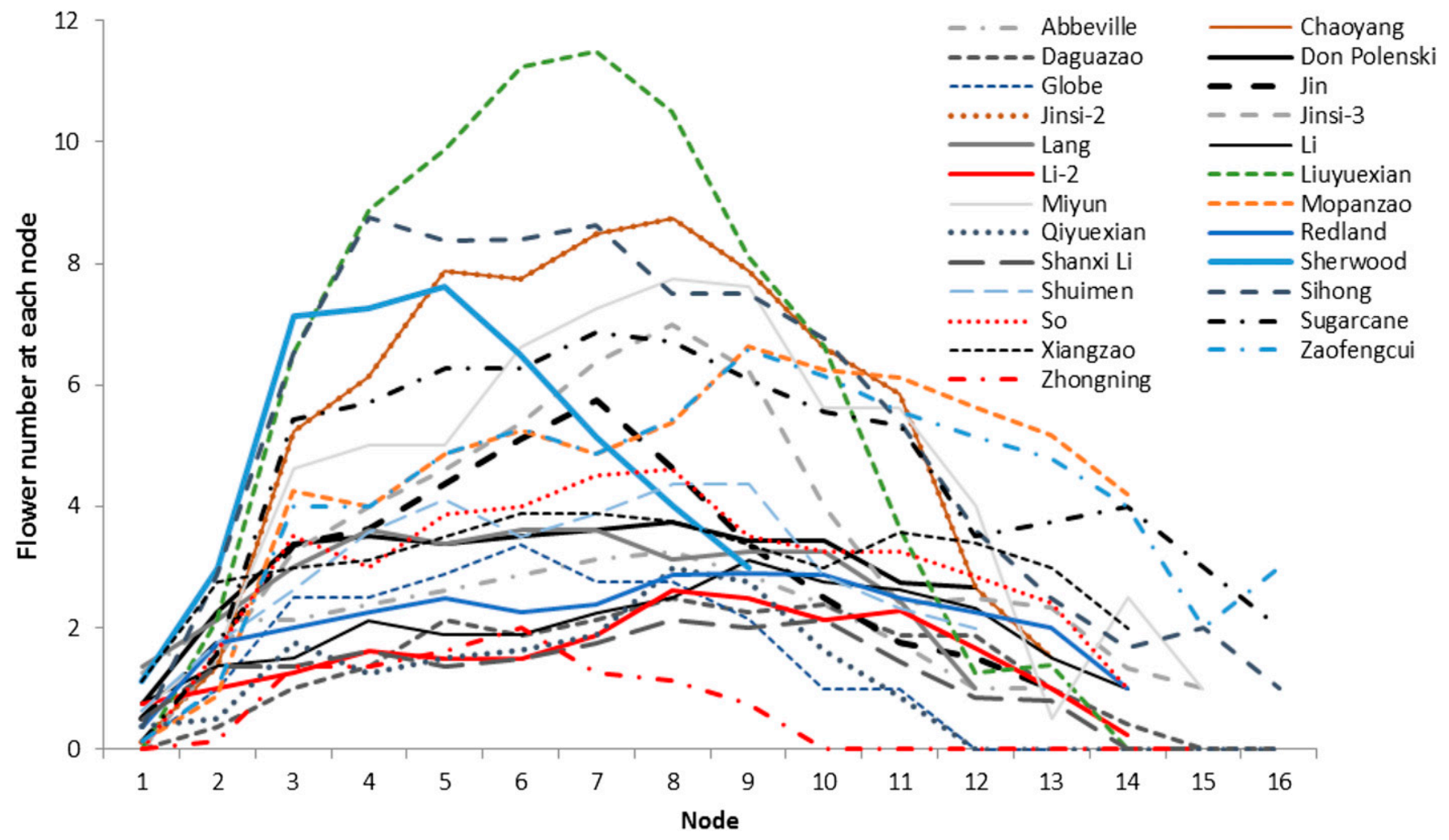

Fig. 1. Flower numbers at each node for different jujube cultivars in June 2012 at Alcalde, New Mexico.

Table 2. Jujube flower diameter of different cultivars at New Mexico State University's Sustainable Agriculture Science Center at Alcalde, New Mexico.

\begin{tabular}{llll}
\hline Cultivar & $\mathrm{mm} \pm \mathrm{SE}$ & \multicolumn{1}{c}{ Cultivar } & $\mathrm{mm} \pm \mathrm{SE}$ \\
\hline GA-866 & $5.0 \pm 0.10$ & Daguazao & $6.3 \pm 0.08$ \\
Mopanzao & $5.1 \pm 0.05$ & Shanxi Li & $6.3 \pm 0.08$ \\
Chaoyang & $5.5 \pm 0.06$ & Jinsi-2 & $6.3 \pm 0.09$ \\
Globe & $5.8 \pm 0.06$ & Redland & $6.3 \pm 0.11$ \\
Zaofengcui & $5.8 \pm 0.06$ & Yuanling & $6.3 \pm 0.11$ \\
Sui & $5.8 \pm 0.07$ & Liuyuexian & $6.4 \pm 0.05$ \\
Banzao & $5.9 \pm 0.04$ & Dabailing & $6.4 \pm 0.07$ \\
Maya & $5.9 \pm 0.06$ & Don Polenski & $6.4 \pm 0.14$ \\
Honeyjar & $5.9 \pm 0.08$ & Sihong & $6.5 \pm 0.07$ \\
So & $6.0 \pm 0.05$ & Zaocuiwang & $6.5 \pm 0.07$ \\
September Late & $6.0 \pm 0.07$ & Hupingzao & $6.5 \pm 0.08$ \\
Sherwood & $6.0 \pm 0.07$ & Youzao & $6.5 \pm 0.08$ \\
Abbeville & $6.0 \pm 0.08$ & Sugarcane & $6.5 \pm 0.11$ \\
Xiangzao & $6.0 \pm 0.11$ & Jinsi-4 & $6.5 \pm 0.14$ \\
Li & $6.1 \pm 0.03$ & Gaga & $6.6 \pm 0.04$ \\
Li-2 & $6.1 \pm 0.09$ & Mu & $6.6 \pm 0.15$ \\
Qiyuexian & $6.1 \pm 0.10$ & Zhongning & $6.7 \pm 0.06$ \\
Fuping & $6.2 \pm 0.06$ & Miyun & $6.7 \pm 0.08$ \\
Kongfucui & $6.2 \pm 0.05$ & Jixin & $6.8 \pm 0.07$ \\
Jin & $6.2 \pm 0.07$ & Xingguang & $6.9 \pm 0.07$ \\
Pitless & $6.2 \pm 0.10$ & Junzao & $6.9 \pm 0.11$ \\
Shuimen & $6.2 \pm 0.11$ & Lang & $7.0 \pm 0.04$ \\
Jinsi-3 & $6.2 \pm 0.12$ & Jing-39 & $7.0 \pm 0.11$ \\
Jinkuiwang & $6.3 \pm 0.05$ & Dragon & $7.0 \pm 0.18$ \\
Average & - & & 6.26 \\
\hline & & &
\end{tabular}

type still bloomed at a similar time after delay. In New Mexico where it is mostly sunny weather, delayed blooming was not common. Even within the same blooming type, some cultivars always bloomed early, whereas others always bloomed late. For the morning type, 'Sugarcane' always bloomed earlier, whereas 'Mu' and 'Jing-39' bloomed later than others.

Flower blooming process. When jujube flower buds were close to bloom, their flower buds turned yellowish in color. The blooming process included the following stages: sepal splitting, sepal flat, petal standing, petal and anther separation, petal flat and anther standing, anther flat, and stigma browning, but the time and duration for each stage varied with cultivar and blooming type (Fig. 2). As sepals split, flowers opened up, and the nectar disk started to exude nectar with morning type peaking in the afternoon and afternoon type peaking the next morning (Fig. 2). The fragrance from the nectar disk attracted insect visitors to the flowers. The color of nectar disk varied with cultivar from light yellow to orange-yellow for ' $\mathrm{Li}$ ' and orange for 'Lang'. As anthesis progressed, the nectar disk color became lighter and lighter until the same color as the sepals after bloom.

Even though there were two blooming types, both released pollen during daytimethe morning type flower released pollen mainly in the afternoon and the afternoon type released pollen from 1600 to $1700 \mathrm{HR}$ and again the next morning. The blooming process lasted for $24 \mathrm{~h}$. For the morning type, the blooming process finished within the same day with no pollen and nectar the next morning, whereas the afternoon type bloomed until noon the next day without much nectar and pollen left. Each flower only bloomed for one day but for each branchlet blooming lasted 4-6 weeks or longer. For trees at Alcalde, New Mexico, blooming continued for up to 2 or 3 months from June to mid-August depending on cultivars, tree age, vigor, and management.

When flowers first opened up, anthers already carried pollen in chunks outside their sacs but the two stigmas were still together and not ready to accept pollen yet. After a few hours (time varied with cultivar), the two stigmas grew, separated, and were ready for pollen (Fig. 3). The two stigmas clearly separated in the late afternoon for the morning type and the next morning for the afternoon type.

Self-pollination/self-fruitfulness. 'Li', 'Li-2', 'Redland', 'Daguazao', 'Qiyuexian', 'Teapot', and 'Xiangzao' were self-fruitful (Table 3). 'Li', 'Li-2', and 'Redland' had higher fruit set with 

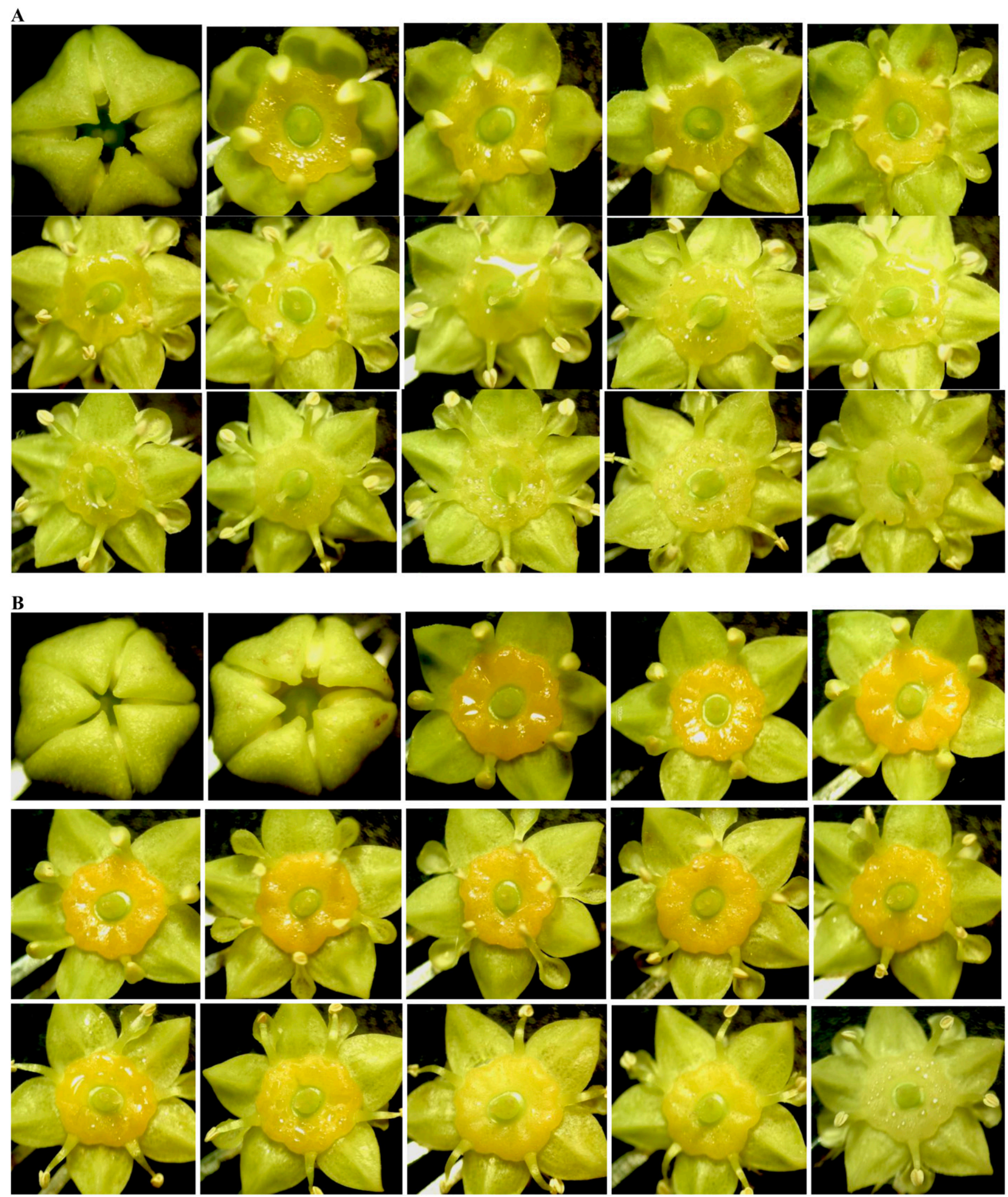

Fig. 2. Jujube flower blooming process for both morning type and afternoon type at Alcalde, New Mexico. (A) Li: Afternoon blooming type, 12 July to 13 July 2013. Row 1: 1300, 1400, 1500, 1600, and $1700 \mathrm{HR}$; Row 2: 0600, 0700, 0800, 0900, and $1000 \mathrm{HR}$; Row 3: 1100, 1200, 1300, 1400, and 1700 HR. (B) Lang: Morning blooming type, 12 July to 13 July 2013. Row 1: 0600, 0700, 0800, 0900, and 1000 HR; Row 2: 1100, 1200, 1300, 1400, and 1500 HR; Row 3: 1600 , $1700,0600,0700$, and $0800 \mathrm{HR}$.

self-pollination than open pollination in 2014. For the remaining cultivars, bagged branchlets had lower fruit set than those with open pollination. Nineteen cultivars had no fruit set after bagging in both 2013 and 2014. Although 'Abbeville', 'Chaoyang', 'Dragon', 'Mopanzao', 'Shanxi Li', 'Sugarcane', 'Youzao', and 'Jinkuiwang' had a low percentage of fruit set from self-pollination in one year, there was no fruit set from self-pollination the next year; further study is needed to confirm or disprove their self-fruitfulness. 'Dabailing' could be 

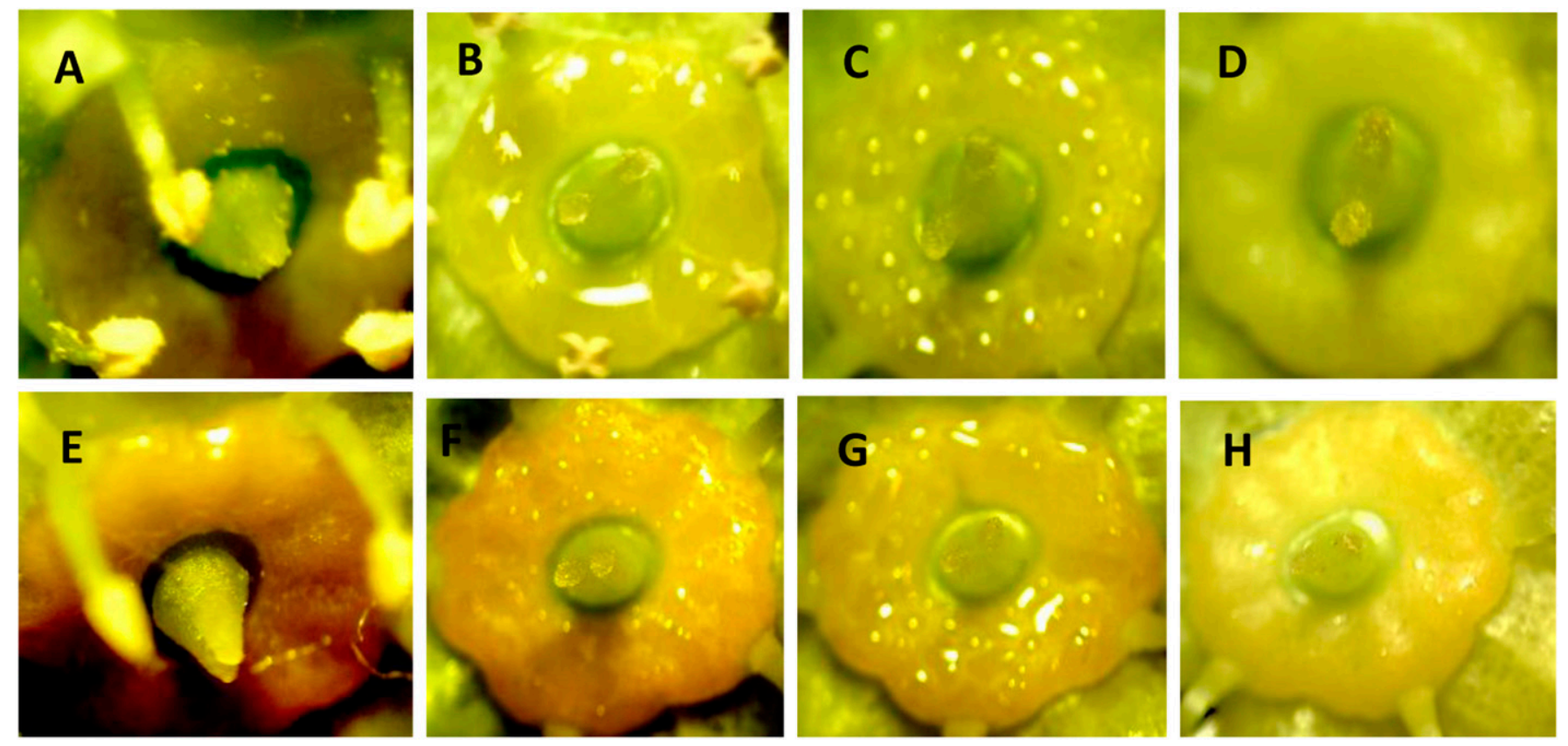

Fig. 3. Stigma changes during flower blooming process for afternoon type 'Honeyjar' and morning type 'Lang'. 'Honeyjar': (A) two stigmas together at 1700 HR; (B) two stigmas separated and disk with plenty of nectar at $0600 \mathrm{HR}$ the next day; (C) stigmas started to turn color at $1200 \mathrm{HR}$; (D) brown stigmas and dry nectar disk at $1700 \mathrm{HR}$, the next day. 'Lang': (E) two stigmas together at $1300 \mathrm{HR}$; (F) two stigmas separated with some nectar at $1500 \mathrm{HR}$; (G) two separated stigmas with plenty of nectar at $1700 \mathrm{HR}$; $(\mathbf{H})$ stigma changing color and no nectar at $0600 \mathrm{HR}$ the next morning.

self-fertile and the zero fruit set in 2013 was due to low and overshaded branches. Commercially popular cultivar 'Lang' was not self-fruitful.

Cultivars had varied fruit set from open pollination (Table 3). 'Abbeville' had the best fruit set at Alcalde among all the cultivars tested (Table 3). Its small fruit is not the most desirable, but it may be used to improve other cultivars' fruit set through breeding. On average, cultivars set better in 2014 than in 2013.

Seed development. Because of the large mesh size of the bags in 2012, insects could touch some flowers from the outside, especially flowers close to the bag. As a result, the fruit set and seed development for bagged branches are not reported. No fruit from bagged branches of any cultivar in both 2013 and 2014 had filled seed, so self-pollinating/ self-fruitful cultivars were not self-fertile in this study at Alcalde, New Mexico.

For open pollination, cultivars were classified into two groups: $<10 \%$ filled seed on average or $>30 \%$ on average. Cultivar seed percentage varied among years (Table 4). Among the cultivars tested, 20 of them were evaluated each year from 2012 to 2014 . Averaging those 20 cultivars, the filled seed percentage was $39.1 \%$ for $2012,32.5 \%$ for 2013 , and $26.3 \%$ for 2014 ; the variation could be related to weather and pollination environment differences. Cultivar Zhongning had the best seed percentage each year, followed by 'Abbeville', 'Jinsi-2', 'Globe', and 'Chaoyang' (Table 4). Fruit of 'Li', 'Li-2', 'Redland', 'Shanxi Li', 'Dabailing', 'Daguazao', and 'Qiyuexian' had very low seed percentage and varied with years. Fruit of 'Lang', 'Don Polenski', 'Junzao', and 'Xingguang' had no fully developed seed during any year (Table 4) seeds stopped their development at an early stage with a dark brown sac residue inside the stone.

\section{Discussion}

Flower number, fruit set, and fruit size. In general, large-fruited cultivars such as 'Li', 'Li-2', and 'Redland' had fewer flowers at each node and lower fruit set per branchlet compared with small-fruited cultivars like 'Fitzgerald'. But 'Abbeville' had very small fruit with only two to three flowers per node, and medium fruit-sized 'Zhongning' also had few flowers. Both 'Abbeville' and 'Zhongning' had good fruit set each year. Flower number is relatively constant for each cultivar and can be used as a supplemental trait for cultivar identification.

Jujube blooming types. Cultivars were classified as morning blooming type or afternoon blooming type in New Mexico (Table 1). In China, they are called day blooming type and night blooming type (Guo and Shan, 2010; Qu et al., 1989). A recent publication also mentioned that in China, the "sepal flat" stage occurred between 0800 to $1130 \mathrm{HR}$ and 1400 to $1600 \mathrm{HR}$ for night blooming type and day blooming type, respectively (Han et al., 2008). Our results are similar to observations in Florida (Lyrene, 1983). There was a 6-h shift between the reported splitting time from China and the United States, which may be related to location and weather conditions (Lyrene, 1983). The morning type in the United States would be equivalent to the night blooming type and the afternoon type is equivalent to the day blooming type in China.

Among the 56 cultivars, 'Chico', 'Edhegard', 'Fitzgerald', 'GI-1183', 'Shuimen'/'Sui', 'So', 'Thornless', 'GA-866', 'Li', and 'Tsao' were the same blooming type as Lyrene (1983) had reported. In New Mexico, 'Lang' was morning type, different from what Lyrene (1983) had reported. 'Lang', 'Don Polenski', and 'Thornless' have similar fruit shape and all were morning blooming type at Alcalde, New Mexico (Table 3). 'Globe', 'Hupingzao', 'Junzao', 'Xiangzao', 'Banzao', 'Chaoyang', 'Dabailing', 'Daguazao', 'Dragon', 'Honeyjar', 'Jin', 'Jinsi-2', 'Jinsi-3', 'Jinsi-4', 'Liuyuexian', 'Qiyuexian', 'Shanxi Li'/'Linyi Li', 'September Late', 'Youzao', 'Yuanling', and 'Zaofengcui' were the same as reported in China with a 6-h shift (Guo and Shan, 2010; Qu and Wang, 1993; Wang et al., 2007). 'Jixin' and 'Mopanzao' were different from reports from China, which could be due to homonym or location differences, and the partial opening of 'Mopanzao' may also lead to misidentification. 'Abbeville', 'Ant Admiral', 'Gaga', 'Jinkuiwang', 'Jing-39', 'Kongfucui', 'Li-2', 'Maya', 'Mu', 'Redland', 'Russia-2', 'Sherwood', 'Sihong', 'Sugarcane', 'Topeka', 'Xingguang', 'Zaocuiwang', and 'Zhongning' are 18 cultivars whose blooming type is being reported for the first time.

Self-pollination, self-fruitfulness, and selffertility. 'Li', 'Li-2', 'Redland', 'Daguazao', 'Qiyuexian', 'Teapot', and 'Xiangzao' were self-fruitful in this study and 'Daguazao' and 'Teapot' were also reported self-fruitful in China (Yan et al., 2010). Our cultivars' selffruitful percentage was much lower than what Yan et al. (2009, 2010) and Liu et al. (2009) reported. This could be due to location, cultivar differences, or tree age. In this study, young trees could underestimate the fruit set percentages, but the bagging material used could also make a significant difference. In our preliminary study in 2012, nylon seed bags with 1- to 2-mm holes were used, and the 
Table 3. Jujube cultivar fruit sets from open pollination and self-pollination with bagging at New Mexico State University's Sustainable Agriculture Science Center at Alcalde, New Mexico, in 2013 and 2014.

\begin{tabular}{|c|c|c|c|c|c|c|c|c|c|c|}
\hline \multirow[b]{2}{*}{ Cultivar } & \multicolumn{2}{|c|}{ Branchlets } & \multicolumn{3}{|c|}{ Fruit/100 branchlets } & \multicolumn{2}{|c|}{ Branchlets } & \multicolumn{3}{|c|}{ Fruit/100 branchlets } \\
\hline & 2013-B & 2014-B & 2013-B & 2014-B & $\operatorname{Avg} \pm \mathrm{SE}$ & $2013-\mathrm{O}$ & $2014-\mathrm{O}$ & 2013-O & 2014-O & $\operatorname{Avg} \pm \mathrm{sE}$ \\
\hline Redland & 76 & 59 & 51.3 & 52.5 & $51.9 \pm 0.8$ & 79 & 55 & 36.7 & 20.0 & $28.4 \pm 11.8$ \\
\hline Li-2 & 59 & 36 & 22.0 & 55.6 & $38.8 \pm 23.8$ & 57 & 32 & 49.1 & 25.0 & $37.1 \pm 17.0$ \\
\hline Qiyuexian & 27 & 32 & 37.0 & 37.5 & $37.3 \pm 0.4$ & 35 & 34 & 97.1 & 185.3 & $141.2 \pm 62.4$ \\
\hline Dabailing & 45 & 49 & 0.0 & 67.3 & $33.7 \pm 47.6$ & 46 & 58 & 8.7 & 127.6 & $68.2 \pm 84.1$ \\
\hline $\mathrm{Li}$ & 102 & 120 & 7.8 & 54.2 & $31.0 \pm 32.8$ & 91 & 137 & 16.5 & 30.7 & $23.6 \pm 10.0$ \\
\hline Xiangzao & 77 & 52 & 7.8 & 21.2 & $14.5 \pm 9.5$ & 92 & 55 & 45.7 & 154.5 & $100.1 \pm 76.9$ \\
\hline Daguazao & 48 & 63 & 4.2 & 23.8 & $14.0 \pm 13.9$ & 54 & 60 & 46.3 & 73.3 & $59.8 \pm 19.1$ \\
\hline Teapot & 30 & 31 & 6.7 & 16.1 & $11.4 \pm 6.6$ & 30 & 32 & 46.7 & 118.8 & $82.8 \pm 51.0$ \\
\hline Mopanzao & 33 & 23 & 18.2 & 0.0 & $9.1 \pm 12.9$ & 40 & 29 & 72.5 & 103.4 & $88.0 \pm 21.8$ \\
\hline Dragon & 33 & 53 & 6.1 & 1.9 & $4.0 \pm 3.0$ & 40 & 38 & 2.5 & 34.2 & $18.4 \pm 22.4$ \\
\hline Abbeville & 77 & 108 & 1.3 & 3.7 & $2.5 \pm 1.7$ & 105 & 115 & 208.6 & 134.8 & $171.7 \pm 52.2$ \\
\hline Youzao & 43 & 26 & 4.7 & 0.0 & $2.4 \pm 3.3$ & 36 & 30 & 36.1 & 106.7 & $71.4 \pm 49.9$ \\
\hline Sugarcane & 92 & 82 & 2.2 & 0.0 & $1.1 \pm 1.6$ & 101 & 75 & 57.4 & 93.3 & $75.4 \pm 25.4$ \\
\hline Chaoyang & 51 & 96 & 2.0 & 0.0 & $1.0 \pm 1.4$ & 40 & 105 & 92.5 & 100.0 & $96.3 \pm 5.3$ \\
\hline Shanxi Li & 103 & 66 & 0.0 & 1.5 & $0.8 \pm 1.1$ & 95 & 74 & 37.9 & 48.6 & $43.3 \pm 7.6$ \\
\hline Don Polenski & 73 & 52 & 0.0 & 0.0 & 0.0 & 75 & 47 & 65.3 & 93.6 & $79.5 \pm 20.0$ \\
\hline GA-866 & 12 & 68 & 0.0 & 0.0 & 0.0 & 54 & 49 & 20.4 & 14.3 & $17.4 \pm 4.3$ \\
\hline Gaga & 31 & 56 & 0.0 & 0.0 & 0.0 & 25 & 58 & 116 & 143.1 & $129.6 \pm 19.2$ \\
\hline GI-1183 & 34 & 59 & 0.0 & 0.0 & 0.0 & 34 & 56 & 32.4 & 37.5 & $35.0 \pm 3.6$ \\
\hline Globe & 81 & 57 & 0.0 & 0.0 & 0.0 & 82 & 55 & 47.6 & 21.8 & $34.7 \pm 18.2$ \\
\hline Honeyjar & 26 & 48 & 0.0 & 0.0 & 0.0 & 37 & 48 & 102.7 & 147.9 & $125.3 \pm 32.0$ \\
\hline Hupingzao & 19 & 55 & 0.0 & 0.0 & 0.0 & 19 & 45 & 63.2 & 11.1 & $37.2 \pm 36.8$ \\
\hline Jin & 96 & 27 & 0.0 & 0.0 & 0.0 & 94 & 29 & 78.7 & 93.1 & $85.9 \pm 10.2$ \\
\hline Jinsi-2 & 53 & 22 & 0.0 & 0.0 & 0.0 & 54 & 30 & 63.0 & 103.3 & $83.2 \pm 28.5$ \\
\hline Jixin & 60 & 91 & 0.0 & 0.0 & 0.0 & 50 & 85 & 28.0 & 49.4 & $38.7 \pm 15.1$ \\
\hline Junzao & 85 & 23 & 0.0 & 0.0 & 0.0 & 81 & 26 & 39.5 & 107.7 & $73.6 \pm 48.2$ \\
\hline Kongfucui & 34 & 60 & 0.0 & 0.0 & 0.0 & 30 & 74 & 56.7 & 106.8 & $81.8 \pm 35.4$ \\
\hline Lang & 79 & 76 & 0.0 & 0.0 & 0.0 & 92 & 83 & 14.1 & 47.0 & $30.6 \pm 23.3$ \\
\hline Maya & 50 & 90 & 0.0 & 0.0 & 0.0 & 46 & 99 & 171.7 & 116.2 & $144.0 \pm 39.2$ \\
\hline Sihong & 34 & 30 & 0.0 & 0.0 & 0.0 & 35 & 27 & 8.6 & 7.4 & $8.0 \pm 0.8$ \\
\hline So & 43 & 119 & 0.0 & 0.0 & 0.0 & 40 & 113 & 15.0 & 36.3 & $25.7 \pm 15.1$ \\
\hline Sui & 49 & 67 & 0.0 & 0.0 & 0.0 & 48 & 57 & 22.9 & 64.9 & $43.9 \pm 29.7$ \\
\hline Xingguang & 49 & 44 & 0.0 & 0.0 & 0.0 & 52 & 50 & 32.7 & 114.0 & $73.4 \pm 57.5$ \\
\hline Zhongning & 62 & 34 & 0.0 & 0.0 & 0.0 & 61 & 46 & 145.9 & 47.8 & $96.9 \pm 69.4$ \\
\hline Jinkuiwang & 41 & - & 7.3 & - & - & 40 & - & 127.5 & - & - \\
\hline September Late & - & 28 & - & 0.0 & - & - & 31 & - & 174.2 & - \\
\hline Jinsi-3 & 40 & - & 0.0 & - & - & 38 & - & 139.5 & - & - \\
\hline Jinsi-4 & 33 & - & 0.0 & - & - & 23 & - & 147.8 & - & - \\
\hline Liuyuexian & 23 & - & 0.0 & - & - & 20 & - & 130 & - & - \\
\hline Pitless & 34 & - & 0.0 & - & - & 46 & - & 163 & - & - \\
\hline Sherwood & 74 & - & 0.0 & - & - & 63 & - & 23.8 & - & - \\
\hline Shuimen & 56 & - & 0.0 & - & - & 65 & - & 58.5 & - & - \\
\hline Zaocuiwang & 27 & - & 0.0 & - & - & 37 & - & 13.5 & - & - \\
\hline Zaofengcui & 48 & - & 0.0 & - & - & 53 & - & 35.8 & - & - \\
\hline
\end{tabular}

$\mathrm{B}=$ Bagged; $\mathrm{O}=$ Open pollination.

The fruit number per 100 branchlets was the fruit count at harvest.

Cultivars with only 1 year's data are listed at the end of table for reference only.

cultivars" "self-fruitful" percentage was much higher (72\%) than in $2013(33 \%)$ and 2014 (30\%) when bags with smaller-sized holes were used. Because of jujube's unique shoot structure and flower development in an inflorescence (Liu, 2006; Yao, 2012a, 2013), it is almost impossible to bag a single flower cluster; a branchlet or the whole secondary branch needs to be bagged. With large holes on the bags and jujube's tiny flowers (Liu, 2006; Yao, 2012a), flowers touching the bags could be pollinated by insects from outside the bag. We observed a wide range of jujube flower insect visitors in New Mexico (Grasswitz and Yao, 2014). Yan et al. (2009, 2010) and Liu et al. (2009) reported that $87.8 \%$ of the 179 cultivars were observed to be self-fruitful. Considering the bags they used had 27.5 holes $/ \mathrm{cm}^{2}$ (1.5-1.8 $\mathrm{mm}$ in length), those cultivars that set a few fruit per 100 branchlets from bagged branches may or may not be from true self-pollination. In this study, with small-holed bags in 2013 and 2014, the self-fruitful cultivar numbers dropped and cultivars performed consistently in both years (Table 3). Guo and Shan (2010) mentioned a high percentage of cultivar self-fruitfulness in commercial production in China. The commercial production in China is different from the case in the United States. Those solid plantings of 'Jinsi' series in Hebei and Shandong provinces in China could be a complex of many strains after thousands of years of production. Their fruit set could be from self-pollination or crosspollination from different strains. Asatryan and Tel-Zur (2013) reported that four Z. jujuba cultivars could set small seedless fruit through controlled self-pollination with $27.8 \%$ fruit set for ' $\mathrm{Li}$ ' and only $2.2 \%$ for 'Lang', and cultivar Tamar was parthenocarpic (fruit set without fertilization of ovules). Lyrene (1983) reported 'Silverhill' and 'Leon Burk' were parthenocarpic (isolated trees set full crop of fully developed fruit whether or not there are viable seeds in the fruit). Different authors classified parthenocarpy differently. From our study without further investigation, we only can conclude ' $\mathrm{Li}$ ', 'Li2', 'Redland', 'Daguazao', 'Qiyuexian', 'Teapot', and 'Xiangzao' were self-pollinating and self-fruitful. More detailed research is needed to find whether they were strictly parthenocarpic (without fertilization process). Most jujube cultivars had viable pollen grains with varying germination rates (Yao, 2012b).

Self-pollinating cultivars 'Li', 'Li-2', and 'Redland' were considered U.S. cultivars. 'Li' was imported 100 years ago and it is hard to find its equivalent in China now. Ackerman (1961) reported that with hand self-pollination, 'Li' had normal fruit set, whereas 'So' and 'Shuimen' had only a few fruit. Our results confirmed that 'Li' was selffruitful in accordance with Ackerman (1961). In Ackerman's experiment, hand self-pollination was conducted while the branches were bagged, whereas our study did not use hand 
Table 4. Percentage of fruit with filled seeds of different cultivars with open pollination at Alcalde, New Mexico, from 2012 to 14.

\begin{tabular}{|c|c|c|c|c|c|c|c|}
\hline & \multicolumn{3}{|c|}{ Fruit number } & \multicolumn{3}{|c|}{ Filled seed (\%) } & \multirow[b]{2}{*}{$\operatorname{Avg} \pm \mathrm{SE}$} \\
\hline & 2012 & 2013 & 2014 & 2012 & 2013 & 2014 & \\
\hline Don Polenski & 11 & 47 & 44 & 0.0 & 0.0 & 0.0 & $0.0 \pm 0.0$ \\
\hline Junzao & 32 & 31 & 28 & 0.0 & 0.0 & 0.0 & $0.0 \pm 0.0$ \\
\hline Lang & 12 & 14 & 38 & 0.0 & 0.0 & 0.0 & $0.0 \pm 0.0$ \\
\hline Xingguang & 8 & 19 & 57 & 0.0 & 0.0 & 0.0 & $0.0 \pm 0.0$ \\
\hline Jin & 13 & 54 & 27 & 0.0 & 3.7 & 0.0 & $1.2 \pm 1.2$ \\
\hline Li-2 & 16 & 27 & $\underline{8}$ & 2.4 & 6.3 & 0.0 & $2.9 \pm 1.8$ \\
\hline Teapot & 20 & 12 & $3 \overline{8}$ & 0.0 & 0.0 & 10.5 & $3.5 \pm 3.5$ \\
\hline Qiyuexian & 8 & 34 & 63 & 0.0 & 2.9 & 7.9 & $3.6 \pm 2.3$ \\
\hline $\mathrm{Li}$ & 26 & 11 & 42 & 0.0 & 9.1 & 2.4 & $3.8 \pm 2.7$ \\
\hline Daguazao & 16 & 16 & 44 & 0.0 & 18.8 & 0.0 & $6.3 \pm 6.3$ \\
\hline Redland & 13 & 21 & 11 & 7.7 & 19.0 & 0.0 & $8.9 \pm 5.5$ \\
\hline Shanxi Li & 25 & 26 & 36 & 24.0 & 3.8 & 0.0 & $9.3 \pm 7.4$ \\
\hline Mopanzao & 12 & 23 & 30 & 100.0 & 34.8 & 10.0 & $48.3 \pm 26.8$ \\
\hline So & 14 & 5 & 41 & 86.0 & 60.0 & 56.1 & $67.3 \pm 9.3$ \\
\hline Sugarcane & 25 & 59 & 71 & 84.0 & 74.6 & 43.7 & $67.4 \pm 12.2$ \\
\hline Chaoyang & 21 & 39 & 107 & 100.0 & 71.8 & 63.6 & $78.5 \pm 11.0$ \\
\hline Globe & 21 & 11 & 12 & 100.0 & 72.7 & 66.7 & $79.8 \pm 10.2$ \\
\hline Jinsi-2 & 31 & 10 & 34 & 90.0 & 88.2 & 74.2 & $84.1 \pm 5.0$ \\
\hline Abbeville & 79 & 209 & 155 & 87.0 & 84.2 & 90.3 & $87.3 \pm 1.8$ \\
\hline Zhongning & 30 & 87 & 22 & 100.0 & 100.0 & 100.0 & $100.0 \pm 0.0$ \\
\hline Average & - & - & - & 39.0 & 32.5 & 26.3 & - \\
\hline Liuyuexian & 11 & 25 & - & 100 & 72 & - & 86.0 \\
\hline Jinsi-3 & 14 & 53 & - & 42.9 & 50.9 & - & 46.9 \\
\hline Shuimen & 22 & 41 & - & 45.5 & 39 & - & 42.3 \\
\hline Dabailing & 19 & - & 74 & 0 & - & 1.4 & 0.7 \\
\hline \multicolumn{8}{|l|}{ September } \\
\hline Late & - & - & 54 & - & - & 96.3 & 96.3 \\
\hline Honeyjar & - & 38 & 71 & - & 100 & 88.7 & 94.4 \\
\hline GI1183 & - & 8 & 21 & - & 100 & 28.6 & 64.3 \\
\hline Jinsi-4 & - & 34 & 14 & - & 97.1 & 50 & 73.6 \\
\hline Jixin & - & 14 & 42 & - & 85.7 & 33.3 & 59.5 \\
\hline Kongfucui & - & 17 & 67 & - & 70.6 & 40.3 & 55.5 \\
\hline Sui & - & 7 & 37 & - & 42.9 & 18.9 & 30.9 \\
\hline Maya & - & 78 & 115 & - & 82.1 & 29.6 & 55.9 \\
\hline Hupingzao & - & 12 & 5 & - & 8.3 & 0 & 4.2 \\
\hline Xiangzao & - & 28 & 85 & - & 67.9 & 12.9 & 40.4 \\
\hline Youzao & - & 13 & 30 & - & 84.6 & 53.3 & 69.0 \\
\hline
\end{tabular}

Cultivars on the lower part of table with 1 or 2 years' data are for reference only.

self-pollination. This plus smaller sample sizes and young trees could have contributed to the difference in results for 'So' and 'Shuimen'. Ackerman (1961) also reported that clones 'G158' and 'G159' sealed in a tent with beehives set normal fruit. 'G158' and 'G159' could be seedlings of the same plant but they cross-pollinated each other, and the solid 'Jinsi' series commercial planting in China could be similar with self-pollination ability or different strains pollinating each other. Like 'Shanxi Li' and 'Abbeville', cultivars with 1-5 fruit/100 branchlets after bagging were below acceptable yield. If they were planted as a solitary tree in the field or backyard without bagging and with enough insect visitors, the fruit set might improve.

Ackerman (1961), Yan et al. (2009, 2010), Liu et al. (2009), and Asatryan and Tel-Zur (2013) all reported self-pollinated fruit were smaller and cross-pollination always increased fruit set and fruit size. The results from this study are similar (data not shown). As a result, commercially, we recommend growers to plant at least two cultivars. Our self-pollination study is useful for researchers and breeders and for guiding home gardeners who may just have room for one tree. Self-fruitful 'Li' would work as a single tree planting, whereas 'Lang' will not.

Seed development. Among the 46 cultivars tested, only a small number of cultivars set fruit by self-pollination and none of the fruit had seed inside the stone from any of the cultivars, which indicates that although some cultivars were self-fruitful, no cultivar was selffertile in this study at Alcalde, New Mexico (Tables 3 and 4). Asatryan and Tel-Zur (2013) also reported four $Z$. jujuba species were selffruitful with varied fruit set but seedless, not self-fertile. Ackerman (1961) reported no fully developed kernels after self-pollination for ' $\mathrm{Li}$ ', 'Shuimen', 'So', 'Yu', 'G11', and '21996' and $1 \%$ filled seeds for 'G144'. Yan et al. (2009, 2010) and Liu et al. (2009) indicated that fruit of 99 cultivars $(84.5 \%)$ had no seeds from selfpollination but the other 17 cultivars had $1 \%$ to $9.9 \%$ seed percentage and 1 cultivar had over $10 \%$ filled seeds from self-pollination. Cultivar differences, favorable weather conditions, and mature trees could be reasons for these higher numbers, and cross-pollination by insects could have occurred through the bags with 1.5 - to $1.8-\mathrm{mm}$ holes. Further experimentation with insectproof bags is needed to confirm those jujube cultivars' self-fertility. The high seed percentage of ' $\mathrm{Li}$ ' from open pollination in California (Ackerman, 1961) could be due to its large sample size and favorable weather conditions, especially during the fruit set period.

Seed percentage from open pollination varied by cultivar and year (Table 4). Cultivar seed development and percentage would be critical information for parent selection in a jujube breeding program (Yan et al., 2009). 'Lang', 'Don Polenski', 'Junzao', and 'Xingguang' had no fully developed seed from open pollination in any years (Table 4). Interestingly, those four cultivars had similar fruit shape. 'Xingguang' is a witches-broom resistant strain from 'Junzao' (Liu et al., 2006), whereas 'Lang' in the United States may not be the same cultivar as 'Lang' in China now. 'Don Polenski' had smaller flowers than 'Lang', whereas 'Lang', 'Xingguang', and 'Junzao' had similar flower diameters. The relationship among 'Lang', 'Junzao', and 'Don Polenski' is not clear. Fruit in 2014 had lower seed percentage than other years in this study. A late frost on 15 May $2014\left(-5.6^{\circ} \mathrm{C}\right)$ could have contributed to the lowest seed percentage in 2014 because frost killed the early growth. The plants regenerated themselves, but the season was delayed. To promote early fruit set after the mid-May frost, water was sprayed over the whole tree twice per week for 2 weeks for all treatments to boost fruit set during the full bloom period, but it did not improve seed development. Cultivars with less than $10 \%$ filled seed would not be suitable as female parents in breeding. We also noticed that early-set and larger fruit had good seed development, whereas some small late-set fruit had only a partially developed stone or was near pitless, especially in 'Lang'.

As a warning, jujubes do have suckers and can become a serious weed if abandoned in hot areas especially in the southeastern United States. In humid and rainy areas, especially with rains around fruit maturation season, fruit cracking/splitting can make the fruit unmarketable. Cracking in most years is not a problem in the semiarid southwest United States.

In summary, this study covers the flowering and fruiting characteristics of the majority of U.S. jujube cultivars. This information would be useful for future jujube-related research, breeding programs, and guiding growers in cultivar selections.

\section{Literature Cited}

Ackerman, W.L. 1961. Flowering, pollination, selfsterility and seed development of Chinese jujube. Proc. Amer. Soc. Hort. Sci. 77:265-269.

Asatryan, A. and N. Tel-Zur. 2013. Pollen tube growth and self-incompatibility in three Ziziphus species (Rhamnaceae). Flora 208:390-399.

Ashton, R. 2006. Jujube-The Chinese date. Third Millennium Publishing, Tempe, AZ.

Ashton, R. 2008. Jujube-A fruit well adapted to Texas. Texas Gardeners. 20 Dec. 2014. $<$ http:// www.texasgardener.com/pastissues/janfeb08/ Jujube.html $>$.

Atkins, J.S. 1987. “He did it again.”. Pomona 20:40-41.

Fairchild, D. 1918. The grafted jujube of China. J. Hered. 9:2-7.

Grasswitz, T. and S. Yao. 2014. Floral visitors to Chinese date (Ziziphus jujuba) in New Mexico and their potential role in pollination. HortScience 49:S397-S398 (abstr.).

Guo, Y. and G. Shan. 2010. The Chinese jujube (in Chinese). Shanghai Scientific and Technical Publishers, Shanghai, China.

Hager, M.D. and T. Edward. 1989. My favorite tree, the jujube. California Rare Fruit Growers Newsletter 21(2):31-32. 
Han, B., J. Li, Z. Xu, and J. Peng. 2008. Studies of blooming biology and pollen sprouting characteristics of different Chinese jujube cultivars (in Chinese). Chinese Agr. Sci. Bul. 24(8):167-170.

Lanham, W.B. 1926. Jujubes in Texas. Texas Agr. Exp. Sta. Circular 41.

Liu, M. 2006. Chinese jujube: Botany and horticulture. Hort. Rev. 32:229-298.

Liu, M. 2008. China jujube development report (in Chinese). China Forestry Publishing House, Beijing, China.

Liu, M., J. Zhou, J. Zhao, J. Wang, P. Liu, L. Da, and Y. Wang. 2006. An excellent new cultivar of Chinese jujube with high resistance to jujube witches broom disease 'Xingguang' (in Chinese). Acta Hort. Sinica 33:683.

Liu, P., M.J. Liu, Z.H. Zhao, X.Y. Liu, J.R. Wang, and C. Yan. 2009. Investigation on the characteristics of fruiting and seed development in Chinese jujube (Ziziphus jujuba Mill.). Acta Hort. 840:209-214.

Locke, L.F. 1948. The Chinese jujube: A promising fruit tree for the southwest, p. 78-81. In: Oklahoma Crops and Soils, 1947: Research reported at the Second Annual Oklahoma Crops and Soils Conference. Oklahoma Agr. Expt. Sta. Bul. B319.
Locke, L.F. 1955. Growing fruits and nuts in the Southern Great Plains. USDA Farmers Bul. No. 2087.

Lyrene, P.M. 1979. The jujube tree. Fruit Var. J. 33:100-104

Lyrene, P.M. 1983. Flowering and fruiting of Chinese jujubes in Florida. HortScience 18:208-209.

Meyer, F.N. 1911. Agricultural explorations in the fruit and nut orchards of China. USDA Bureau of Plant Industry Bul. No. 204. 26 Jan. 2015. <http://books.google.com/books?id= GqQUAAAAYAAJ\&printsec $=$ frontcover \& source $=$ gbs_ge_summary_r $\&$ cad $=0 \# v=$ onepage $\&$ $\mathrm{q} \& \mathrm{f}=$ false $>$.

Meyer, F.N. 1916. China, a fruitful field for plant exploration. U.S. Dept. Arg. Yearbook 1915: 205-224.

Qu, Z. and Y. Wang (eds.). 1993. Chinese fruit trees record-Chinese jujube (in Chinese). The Forestry Publ. House of China, Beijing, China.

Qu, Z., Y. Wang, J. Zhou, S. Peng, X. Qi, S. Cheng, and M. Liu. 1989. The observation of flowering characteristics of Chinese jujube (in Chinese). J. Hebei Agr. Univ. 12(1):1-9.

Sweet, C. 1985. Large market potential seen for the chinese date (jujube). California Grower: Avocados, Citrus, Subtropicals 12(9):41-43, 48.
Thomas, C.C. 1924. The Chinese jujube. U.S. Dept. Agr. Bul. 1215.

Wang, B., M. Yang, Y. Wang, C. Zhou, X. Bu, and J. Liu. 2007. An early jujube cultivar Zaofengcui (in Chinese). China Fruits 2007(5):6-8.

Yan, C., P. Liu, M. Liu, J. Wang, D. Kong, and D. Li. 2010. The influencing factors of the fruiting characteristics of Ziziphus jujube (in Chinese). Scientia Silviae Sinicae 46(4):78-86.

Yan, C., P. Liu, M. Liu, J. Wang, D. Li, and D. Kong. 2009. Characteristics of fruiting and fertility of different cultivars of Ziziphus jujuba Mill (in Chinese). J. Plant Genetic Resources 10(1): 121-125.

Yao, S. 2012a. Jujube, Chinese date in New Mexico. New Mexico State Univ. Coop. Ext. Publ. H-330.

Yao, S. 2012b. Jujube flowering and pollen germination. HortScience 47:S301 (abstr.)

Yao, S. 2013. Past, present and future of jujube, Chinese dates in the United States. HortScience 48:672-680.

Yao, S. 2015. Jujube (Ziziphus jujuba) in the United States: Challenges and opportunities. Third International Jujube Symposium. Acta Hort. (In press). 